\title{
THE ROLE OF TOBACCO CONTROL POLICIES IN REDUCING SMOKING AND DEATHS CAUSED BY SMOKING IN AN EASTERN EUROPEAN NATION: RESULTS FROM THE ALBANIA SIMSMOKE SIMULATION MODEL
}

\author{
David T. Levy ${ }^{1}$, Hana Ross ${ }^{2}$, Eduard Zaloshnja ${ }^{1}$, Roland Shuperka ${ }^{3}$, Meriglena Rusta ${ }^{3}$ \\ ${ }^{1}$ Pacific Institute for Research and Evaluation, Calverton, Maryland, USA \\ ${ }^{2}$ International Tobacco Control Research, American Cancer Society, Atlanta, USA \\ ${ }^{3}$ For a Tobacco-Free Albania, Tirana, Albania
}

\begin{abstract}
SUMMARY
The Albania SimSmoke simulation model is used to examine the effects of tobacco control policies. The model is used to consider the projected trends in smoking prevalence and associated smoking-attributable deaths in the absence of new policies, and then to examine the effect of new policies that are consistent with the Framework Convention for Tobacco Control (FCTC) on these outcomes.

The model shows that significant inroads to reducing smoking prevalence and premature mortality can be achieved through tax increases. A comprehensive strategy to further reduce smoking rates should include a media campaign complete with programs to publicize and enforce clean air laws, a comprehensive cessation treatment program, strong health warnings, advertising bans, and youth access laws.

Besides presenting the benefits of a comprehensive tobacco control strategy, the model helps to identify important information needed for both modeling and policymaking. The effectiveness of future tobacco control policy will require proper surveillance and evaluation schemes for Albania.
\end{abstract}

Key words: tobacco control policy, FCTC, simulation model, Albania

Address for correspondence: D. T. Levy, Pacific Institute for Research and Evaluation, 11720 Beltsville Dr., Suite 900, Calverton, Maryland, 20705, USA. E-mail: Levy@pire.org

\section{INTRODUCTION}

Smoking is the most preventable cause of premature mortality, increasing the risk of lung cancer, emphysema, heart disease, stroke, and other diseases $(1,2)$. Globally, it is estimated that 4 million deaths each year are attributable to smoking, with trends driving a rise to 10 million deaths per year by the 2030s (3). In Eastern Europe, the problem is particularly serious with $20 \%$ of all men age 35 expected to die from a tobacco-related illness by age 69. This is twice the rate of Western Europe, as smoking alone explains much of the East-West mortality gap amongst men (4).

Most nations in Western Europe have smoking rates below $25 \%$, such as Sweden which has 16\%, while nations in Eastern Europe generally have smoking rates above $30 \%$. Albania, Armenia, Belarus, Georgia, and the Russian Federation have documented male smoking rates above 50\% in 1990's (http://data.euro.who. int/tobacco/Default.aspx?TabID=2444). While female smoking rates are lower in these nations, their rates have been rising.

Most Eastern European nations have signed the FCTC, developed through the World Health Organization. The FCTC proposes higher tobacco taxes, smoke-free indoor air laws, strong advertising restrictions and health warnings, cessation treatment coverage, and a well organized information campaign to curb the smoking epidemic. Substantial evidence indicates that these policies can substantially reduce adult smoking rates, especially when combined as a comprehensive strategy (5-8). They not only reduce smoking initiation, but also motivate current smokers to quit. Quitting can halt or even reverse many of the health problems associated with smoking $(2,9)$.

The FCTC was signed by Albania in 2004 and ratified in 2006. A survey conducted in Albania in 1999 and 2000 found that $60 \%$ of males and $18 \%$ of females were regular or occasional smokers (10). Until recently, Albania has also had weak tobacco control policies: low taxes, weak clean air laws, no concerted media campaign or cessation treatment policy, and weak health warnings and advertising restrictions. Albania increased cigarette taxes in 2006, and, in 2007, banned billboard tobacco advertisements, smoking in public places, and sales of tobacco products to those under 18-year-old. These policies provide a start, but represent only part of the policies enumerated in the FCTC. To support implementation of the FCTC in Albania, evidence on the effectiveness of policies and guidance on the appropriate mix of policies will be required.

Most statistical studies have examined the effect of only one or at most two tobacco control policies (11-13), because the ability 
to distinguish among the effects of more than one tobacco control policy is often limited. Simulation models combine information from different sources to examine how the effects of public policies will unfold over time in complex social systems $(14,15)$. Models have been developed by Mendez and Warner (16, 17), Tengs et al. (18, 19), Ahmad et al. (20-22) and Levy et al. (15, 23-25) to show the effect of tobacco control policies on smoking prevalence and health outcomes. The SimSmoke model of Levy et al. considers a broader array of public policies than the other afore-mentioned models (26).

This study documents the results of the Albania SimSmoke simulation model. It is patterned after SimSmoke, a tobacco control policy model developed for the US and other nations. Using population, smoking rates, and tobacco control policy data for Albania, the model predicts future smoking rates and the number of deaths attributable to smoking. The model also assesses the effect of FCTC-consistent tobacco control policies, individually and combined, on these outcomes. Albania SimSmoke shows that the effect of policies depends on a population's composition, the manner in which policies are implemented, the existence of other policies, and the length of time that policies are in effect. The model also provides guidance on the types of data needed for the effective surveillance and evaluation of policies.

\section{METHODS}

\section{Basic Model}

SimSmoke contains a population model, a smoking model, a smoking-attributable death model, and policy modules (15, $24,25)$. Simsmoke begins in a baseline year with the population divided into smokers, never smokers, and previous smokers by age and gender. Because a large scale survey of smoking behavior was conducted in 2007, that year was chosen as the baseline. From the base year to future years, a discrete time, first order Markov process is employed to project future population growth and smoking rates. Population growth changes through fertility and deaths, and smoking rates change through to smoking initiation, cessation, and relapse rates. Smoking rates also change over time through changes in tobacco control policies.

\section{Population Model}

Population data by age and gender were obtained from the Albania 2001 Census (proprietary file of the Albanian Institute of Statistics). Data on 2005 mortality and fertility rates were obtained from the Albanian Institute of Statistics. International migration wasn't considered based on its small influence (www.theodora. com/wfbcurrent/albania/albania_population.html).

\section{Smoking Model}

Individuals are categorized as having never smoked from birth until they either initiate smoking or die. They may progress from smoker to ex-smoker through cessation and may return to smoking through relapse. Relapse occurs based on the number of years since quitting.

The data on baseline smoking is from a face-to-face survey of households conducted between April 21, 2007 and May 6, 2007, yielding 4,000 completed interviews of adults (age 18 and above). The sample was selected by first dividing the population of each district and strata into 7,823 primary sampling units (PSUs), from which 250 urban and 250 rural PSUs were chosen. Next, 8 households were chosen randomly from each PSU.

In the survey, individuals were first asked if they currently smoke cigarettes daily, less than daily, or not at all. Those who answered "yes" to smoking regularly or occasionally are considered current smokers. Those who did not currently smoke were then asked if they have ever smoked in their lifetime to distinguish between never smoked and ex-smokers. Ex-smokers were asked to report how long it has been since they stopped smoking, which was used to distinguish those who quit within the last year from those who quit more than one year. Using relative portions obtained from the US data., ex-smokers were further distinguished by years since they quit through 15 years and above.

Due to empirical challenges measuring initiation and cessation and to insure stability in the model, initiation rates at each age are measured as the difference between the smoking rate at that age and the rate at the previous age. Based on an examination of prevalence data and the average age of initiation, smoking rates began to level off at age 22 for females and 27 for males, so initiation occurs in the model up to these ages.

One-year cessation rates were calculated as those who were smoking one year ago and are currently not smoking divided by those who were smokers one year ago (including those who quit in the last year). There was a relatively consistent first year cessation rate obtained across age groups, $2 \%$ for males and less than $1 \%$ for females. Cessation is tracked from age 25, since smoking before that age is less likely to have health implications for ex-smokers. Because data were not available for Albania, relapse rates were used for the US $(1,2,27,28)$.

\section{Smoking-Attributable Deaths}

Like standard attribution measures (29, 30), smoking-attributable deaths in the SimSmoke model are calculated by finding the death rates of those who have never smoked, smokers, and ex-smokers by using smoking prevalence rates and the relative risks of smokers and ex-smokers relative to those who have never smoked. The number of smokers at each age is then multiplied by the death rate of smokers minus the death rate of those who have never smoked to obtain the excess deaths that have resulted from smoking. The same procedure is applied to each ex-smoker group using the ex-smoker death rate. The excess deaths of smokers and ex-smokers are summed for all ages to obtain the number of smoking attributable deaths.

Deaths rates by age and gender are calculated using the above-mentioned death rates and smoking rates for Albania. For smokers' relative risks of total mortality, Wen et al. (31) obtained an estimate of 1.55 for Taiwan, as did Jee et al. (32) for Korea. Because these nations have a similar level of economic development, background risks, and smoking history to that of Albania, the model uses 1.55 as the relative risk of smoking for all ages. Since relative risks may rise in the future as younger cohorts, who have initiated smoking earlier and smoke more cigarettes, begin to age (33), we also consider a relative risk of 2.4, based on the US $(1,34,35)$. For ex-smokers, relative risks are assumed to decline at the rate observed in the US $(2,35)$. 


\section{Policies}

The effects of price interventions (taxes), clean indoor air laws, mass media policies, advertising bans, warning labels, cessation treatment policies, and strategies to reduce youth access to cigarettes are modeled. The policies are summarized in Table 2 . The parameters used to generate the predicted policy effects are based on thorough reviews of the literature $(6,36-41)$ and advice of an expert panel. In addition, policies and studies or factors relevant to the effects of policies in Albania are considered. Information was obtained from the National Tobacco Information Online System (apps.nccd.cdc.gov/nations/) and staff in Albania.

The effects of stronger policies are calculated as percent reductions $(\mathrm{PR})$ relative to the initial rates, i.e., $[\mathrm{PR}=$ (post-policy rate - initial rate)/initial rate, where $\mathrm{PR}<0$ ]. Policies generally have their greatest effect in the initial years. The effects are modeled as a permanent additive effect on smoking prevalence in the first year that the policy is implemented, i.e., Smokers Sma $_{t,}\left(1+\mathrm{PR}_{\mathrm{i}, \mathrm{t}}\right)$ for policy $\mathbf{i}$ at time period $\mathbf{t}$. After the first year, policies affect the initiation and cessation rates. Throughout the years in which the policy is in effect, a percentage reduction in the initiation rate [as Initiation rate $\left.*\left(1+\mathrm{PR}_{\mathrm{i}}\right)\right]$ sustains the effect of the policy. The effects of each policy, except youth access, are augmented over the same time period through increases in the first year cessation rate [as Cessation rate ${ }_{a}^{*}\left(1-\mathrm{PR}_{\mathrm{i}}\right)$ ]. First year quit rates are elevated due to the higher propensity to quit among individuals who smoke less (42-44) and economic and informational factors. It is assumed that the rates of relapse are unaffected by policy changes. When more than one policy is in effect, it is assumed that there are constant proportional reductions, i.e., $\left(1+\mathrm{PR}_{\mathrm{i}}\right) *\left(1+\mathrm{PR}_{\mathrm{j}}\right)$ for policies $\mathbf{i}$ and j. This formulation implies that the relative effect of a policy is independent of other policies that are in effect.

\section{Tax and Price Policies}

Based on economic theory, cigarette use in SimSmoke is determined by the retail price relative to the prices of other goods. The effect of price on smoking rates is related through an equation that depends on the participation (i.e., prevalence) demand elasticities (45). Studies of cigarette demand indicate that more developed countries have price elasticities of - 0.4 compared to -0.8 for less developed countries $(46,47)$. No demand study has been conducted for Albania, but the lower incomes in Albania would tend to increase the elasticity relative to the US while higher taxes may be avoided through smuggling. Albania SimSmoke distinguishes the price elasticity by age based on previous US studies (46). For males and females (46), a prevalence elasticity is assigned of -0.4 to those through age 24 and of -0.2 for those ages 25 and above.

The price per pack of cigarettes (lek 125) in Albania was calculated as the average price that smokers from the smoking survey paid and includes an excise tax of lek 42. In the model, prices increase in absolute terms with the amount of the cigarette tax $(46,48)$, and the taxed and non-taxed portions of price increase with the rate of inflation.

\section{Clean Air Laws}

The clean air policy module examines the effect of laws for work sites, restaurants, and other public places. Compared to no clean air laws, the module for the US predicts a $10 \%$ reduction in prevalence rates with complete bans, strong enforcement, and media publicity (49). Among clean air policy laws, work site laws yield a $6 \%$ reduction, restaurant laws $2 \%$, and laws covering other places $1 \%$. Media publicity and enforcement yield an additional $0.5 \%$ effect for both work sites and restaurants.

No studies of clean air laws have been conducted for Albania, but the percent employed and the percent who work outdoors were considered. In 2006, approximately 58\% of the Albania workforce was employed in agriculture compared to about $2 \%$ in the US. Compared to the US, the unemployment rate in Albania was high (at least 14\% and possibly as high as 35\%) (www.theodora.com/ wfbcurrent/albania/albania_economy.html). Since much of the effect of a worksite ban is through anti-smoking norms, the US effect is scaled by $60 \%$ to reflect the higher percent of Albanians who work in agriculture and the lower labor participation rate. Bans for restaurants and other public places are assigned to have the same effect in Albania as in the US.

Prior to 2007, there were limited restrictions on smoking in public. Those that existed were in hospitals and public workplaces, and were voluntary. In May 2007, smoking in restaurants and other public places was banned. In their first year, there appeared to be limited enforcement of these laws. The 2007 policies are incorporated in the base model as if they were implemented in 2008 since the smoking survey upon which smoking rates are based was taken before their implementation.

\section{Mass Media Policies/Campaigns}

The model distinguishes two levels of mass media policies/ campaigns; a highly publicized media campaign (appearing at least two months of the year on television, but also present on other media), and a low publicity media campaign (publicized only sporadically in newspapers, billboards, or some other media). At each of these levels, the effects depend on whether other policies, such as tax increases, cessation programs, and clean air initiatives, are in effect, because of a synergistic effect of the publicity (e.g., in the newspaper or on television) that they generate.

The effectiveness of mass media policies in the US SimSmoke model is based largely on recent experiences in California, Massachusetts, and other US states, and campaigns from other developed countries (50). With other policies implemented, a highly publicized campaign yields a $6.5 \%$ reduction in smoking rates, reduced to a $1.3 \%$ effect for a low publicized campaign. In the absence of other policies, these effects are halved. In Albania, the ability to affect smokers may be greater than in the US due to a lower general level of awareness about the dangers of smoking. The benefits may be greatest in rural areas, but the ability to effectively reach rural populations may be low. Therefore, the effects for the US are also assigned for Albania.

Although Albania has had quit and win campaigns and other publicity about the dangers of tobacco, there has been a limited mass media campaign. According to the 2003 Global Youth Tobacco Survey (GYTS) (www.cdc.gov/tobacco/global/GYTS/ factsheets/euro/2003/albaniafactsheet.htm), Albanian youth reported seeing antismoking media messages on TV (76\%), billboards (67\%), and in newspapers and magazines (59\%). Albania is characterized as having a low intensity campaign.

\section{Advertising and Marketing Bans}

To be effective, advertising (television, radio, print, billboard, in-store displays) and other marketing (brand stretching, free 
cigarettes and other promotions) bans must be comprehensive. In the US SimSmoke, a ban on all marketing and advertising leads to a $6 \%$ reduction in prevalence, a $3 \%$ increase in the cessation rates, and an $8 \%$ reduction in initiation, while a total ban of advertising only leads to a $4 \%$ reduction in prevalence, a $2 \%$ increase in cessation rates, and a $6 \%$ reduction in initiation. A partial ban leads to a $1 \%$ reduction in prevalence and initiation only. The larger effects on initiation reflect that youth appear to be particularly amenable to advertising (6). Vigilant monitoring and enforcement of a comprehensive ban adds $2 \%$ to the effects of prevalence and initiation. The same effects are assigned for Albania.

In 2000, Albania imposed a ban on tobacco advertising in local magazines, newspapers, television, and radio. There was no ban on indirect marketing (sponsorships, free samples or promotional discounts), billboard or point of sale advertising, and cigarettes were advertised on commonly watched foreign TV stations and in international magazines received by Albanians. According to the 2003 GYTS, youth were exposed to pro-tobacco ads on TV (78.6\%), billboards (82.3\%), and in newspapers and magazines (74.7\%), and $23.6 \%$ have an object with a cigarette brand logo and $16.3 \%$ have been offered free cigarettes by a tobacco company representative. This level is classified as between a partial and total ban (50\% of the partial effect and $50 \%$ of the total effect). In 2007, tobacco billboard advertising, a commonly used form of advertising in Albania, was banned, which is classified as a complete advertising ban starting in 2008 .

\section{Health Warnings}

In SimSmoke, health warnings are defined as either weak or strong. A strong warning is bold and graphic and covers at least one fourth of the front of a package. In the US model, weak warnings reduce the prevalence and initiation rate by $1 \%$ and increase the cessation rate by $1 \%$, while strong health warnings reduce the initiation and prevalence rates by $2 \%$ and increase the cessation rate by $4 \%$. Health warnings are expected to primarily affect the cessation rate because they provide continuous warnings to the smoker. By reinforcing the message found on the package, publicity, especially through media campaigns directed at the health effects of smoking, increases the effectiveness of health warnings by $1 \%$. While the awareness about health dangers may be lower in Albania than the US, the same parameters are used for Albania. In Albania, warnings were required to cover a small part of the package and included no pictorial, which is classified as a weak warning. No publicity accompanies the warnings.

\section{Youth Access}

Youth access policies are directed at youth purchases of tobacco. The youth access module considers that youth often obtain their cigarettes from non-retail sources. In the US, this limits the effect to a maximum $40 \%$ reduction in youth prevalence for those ages $10-15$ and a $20 \%$ reduction for those ages 16-17 when youth access laws are strongly enforced. The 2003 GYTS (www.cdc.gov/tobacco/global/GYTS/factsheets/euro/2003/albania_factsheet.htm) indicates that $44.5 \%$ of Albanian youth buy cigarettes in a store. Because these patterns are similar to those in the US, the same parameters are assumed for Albania.

Albania implemented a ban on youth purchases of tobacco in 2007. The 2003 GYTS found that $85 \%$ of youth who buy cigarettes in a store were not refused purchase because of their age. Albania is characterized as having no youth access enforcement.

\section{Cessation Treatment}

The cessation treatment policy module in SimSmoke $(51,52)$ considers the effects of 1 . mandated brief interventions from health care providers to encourage patients to quit smoking, 2. complete financial coverage of cessation treatments, and 3. active quitlines with follow-up sessions and no cost NRT provided to callers.

Behavioral or pharmacotherapy use are assumed to double quit rates, and their combined use quadruples quit rates (53). Brief interventions increase quit rates by $30 \%$ and active quitlines with follow-ups double quit rates (54). Well publicized quitlines with no-cost NRT attract $8 \%$ of smokers (55). With complete access to treatments and brief interventions by health care providers, an additional 5.5\% of smokers use cessation treatment alone, 1.7\% use behavioral treatment alone, and $2.8 \%$ use combined pharmacotherapy and behavioral treatment. Of those who use quitlines and treatments as result of the policies, it is assumed that $50 \%$ would not otherwise have made a quit attempt. As a result of all of the policies, smoking prevalence is reduced by $3.5 \%$ in the first year and first year quit rates increase by $50 \%$ in future years.

Albania has a quitline but it is not active or well publicized. Data from the 2007 smoking survey indicates that only half of Albanians saw a doctor in the last year and half of those received a brief intervention. Current cessation policies are considered negligible.

\section{The Effect of Tobacco Control Policies}

The simulation model was programmed using Excel software. First, the effects of the policies that were already implemented in 2007 (after the survey was taken) on future smoking rates and deaths attributable to smoking were considered. Next, the effects of implementing stricter policies consistent with the FCTC guidelines were considered. These include tax increases, strict clean air laws, advertising bans, strong health warnings, a highly publicized media campaigns, strict youth access enforcement, and a comprehensive smoking cessation treatment program. The impact of implementing these policies was examined both individually and in combination beginning in the year 2008 and continuing through future years.

\section{RESULTS}

The estimates of adult (age 18 and above) smoking prevalence under the status quo and varying policy scenarios both individually and in combination are shown in Tables $1 \mathrm{a}$ and $1 \mathrm{~b}$ for males and females, respectively. The total number of projected deaths attributable to smoking is displayed for the different policies in Table 2a and $2 \mathrm{~b}$ for males and females, respectively.

\section{Status quo Scenarios}

If tobacco control policies remained unchanged from their initial 2007 levels (before the 2007 policy changes), the male smoking prevalence is projected to decline in absolute terms by $0.3 \%$ between 2007 and 2008 , from $64.4 \%$ to $64.1 \%$. In terms of future predicted changes from 2007, male smoking prevalence is 
Table 1a. Smoking prevalence rates predicted under status quo and under different policy scenarios for males, 2007-2027*

\begin{tabular}{|c|c|c|c|c|c|c|c|}
\hline Policy in place & 2007 & 2008 & $\begin{array}{l}\text { Relative } \\
\text { difference in } \\
2008^{* \star}\end{array}$ & 2012 & 2017 & 2027 & $\begin{array}{c}\text { Relative } \\
\text { difference in } \\
2027^{* *}\end{array}$ \\
\hline Status quo in 2007 & $64.4 \%$ & $64.1 \%$ & & $63.0 \%$ & $62.2 \%$ & $61.5 \%$ & \\
\hline Status quo with new policies & $64.4 \%$ & $62.2 \%$ & & $61.0 \%$ & $60.0 \%$ & $59.1 \%$ & \\
\hline Lek 25 tax increase ${ }^{\star \star \star}$ & $64.4 \%$ & $59.7 \%$ & $-4.0 \%$ & $58.3 \%$ & $57.2 \%$ & $55.9 \%$ & $-5.3 \%$ \\
\hline Lek 75 tax increase ${ }^{\star \star *}$ & $64.4 \%$ & $56.1 \%$ & $-9.8 \%$ & $54.5 \%$ & $53.0 \%$ & $51.4 \%$ & $-13.0 \%$ \\
\hline Lek 125 tax increase ${ }^{\star \star \star}$ & $64.4 \%$ & $53.6 \%$ & $-13.8 \%$ & $51.8 \%$ & $50.2 \%$ & $48.3 \%$ & $-18.2 \%$ \\
\hline Lek 175 tax increase ${ }^{\star \star \star}$ & $64.4 \%$ & $51.8 \%$ & $-16.7 \%$ & $49.9 \%$ & $48.1 \%$ & $46.1 \%$ & $-22.0 \%$ \\
\hline Clean air laws & $64.4 \%$ & $59.8 \%$ & $-3.9 \%$ & $58.6 \%$ & $57.6 \%$ & $56.6 \%$ & $-4.2 \%$ \\
\hline Media campaign & $64.4 \%$ & $60.5 \%$ & $-2.7 \%$ & $59.3 \%$ & $58.3 \%$ & $57.4 \%$ & $-2.9 \%$ \\
\hline Marketing ban & $64.4 \%$ & $61.0 \%$ & $-2.0 \%$ & $59.8 \%$ & $58.8 \%$ & $57.8 \%$ & $-2.1 \%$ \\
\hline Strong health warnings & $64.4 \%$ & $61.6 \%$ & $-1.0 \%$ & $60.3 \%$ & $59.3 \%$ & $58.3 \%$ & $-1.3 \%$ \\
\hline Cessation treatment program & $64.4 \%$ & $60.0 \%$ & $-3.5 \%$ & $58.6 \%$ & $57.5 \%$ & $56.4 \%$ & $-4.5 \%$ \\
\hline Youth access & $64.4 \%$ & $62.2 \%$ & $0.0 \%$ & $60.8 \%$ & $59.6 \%$ & $58.6 \%$ & $-0.9 \%$ \\
\hline All of above w/ lek 75 tax increase & $64.4 \%$ & $45.0 \%$ & $-27.7 \%$ & $42.8 \%$ & $41.1 \%$ & $39.1 \%$ & $-33.9 \%$ \\
\hline All above w/ lek 125 tax increase & $64.4 \%$ & $43.0 \%$ & $-31.0 \%$ & $40.7 \%$ & $38.9 \%$ & $36.6 \%$ & $-38.0 \%$ \\
\hline All of above w/ lek 175 tax increase & $64.4 \%$ & $41.5 \%$ & $-33.3 \%$ & $39.2 \%$ & $37.3 \%$ & $34.9 \%$ & $-41.0 \%$ \\
\hline
\end{tabular}

${ }^{*}$ Prevalence rates as a percent of the adult (18+) population.

** Measured relative to the status quo in the same year, i.e., (SRp,t-SRStatus quo,t)/ SRStatus quo,t, where SRp,t is the smoking rate in year $t$ with policy $p$ and SRStatus quo, $t$ is the smoking rate in year $t$ with status quo.

*** Tax increase is relative to the lek 125 price and is adjusted upward with inflation over time.

Table 1b. Smoking prevalence rates predicted under status quo and under different policy scenarios for females, 2007-2027*

\begin{tabular}{|c|c|c|c|c|c|c|c|}
\hline Policy in place & 2007 & 2008 & $\begin{array}{l}\text { Relative } \\
\text { difference in } \\
2008^{* *}\end{array}$ & 2012 & 2017 & 2027 & $\begin{array}{l}\text { Relative } \\
\text { difference in } \\
2027^{\star *}\end{array}$ \\
\hline Status quo in 2007 & $18.9 \%$ & $19.0 \%$ & & $18.9 \%$ & $18.9 \%$ & $18.9 \%$ & \\
\hline Status quo with new policies & $18.9 \%$ & $18.4 \%$ & & $18.3 \%$ & $18.2 \%$ & $18.2 \%$ & \\
\hline Lek 25 tax increase ${ }^{\star \star \star}$ & $18.9 \%$ & $17.7 \%$ & $-4.1 \%$ & $17.5 \%$ & $17.3 \%$ & $17.2 \%$ & $-5.6 \%$ \\
\hline Lek 75 tax increase ${ }^{\star \star \star}$ & $18.9 \%$ & $16.6 \%$ & $-10.0 \%$ & $16.3 \%$ & $16.0 \%$ & $15.7 \%$ & $-13.7 \%$ \\
\hline Lek 125 tax increase ${ }^{\star \star \star}$ & $18.9 \%$ & $15.8 \%$ & $-14.1 \%$ & $15.5 \%$ & $15.1 \%$ & $14.7 \%$ & $-19.1 \%$ \\
\hline Lek 175 tax increase ${ }^{\star \star \star}$ & $18.9 \%$ & $15.3 \%$ & $-17.2 \%$ & $14.9 \%$ & $14.5 \%$ & $14.0 \%$ & $-23.0 \%$ \\
\hline Clean air laws & $18.9 \%$ & $17.7 \%$ & $-3.9 \%$ & $17.6 \%$ & $17.5 \%$ & $17.5 \%$ & $-4.0 \%$ \\
\hline Media campaign & $18.9 \%$ & $17.9 \%$ & $-2.7 \%$ & $17.8 \%$ & $17.7 \%$ & $17.7 \%$ & $-2.8 \%$ \\
\hline Marketing ban & $18.9 \%$ & $18.1 \%$ & $-2.0 \%$ & $17.9 \%$ & $17.8 \%$ & $17.9 \%$ & $-2.1 \%$ \\
\hline Strong health warnings & $18.9 \%$ & $18.2 \%$ & $-1.0 \%$ & $18.1 \%$ & $18.0 \%$ & $18.0 \%$ & $-1.1 \%$ \\
\hline Cessation treatment program & $18.9 \%$ & $17.8 \%$ & $-3.5 \%$ & $17.6 \%$ & $17.4 \%$ & $17.3 \%$ & $-4.5 \%$ \\
\hline Youth access & $18.9 \%$ & $18.4 \%$ & $0.0 \%$ & $18.3 \%$ & $18.1 \%$ & $18.1 \%$ & $-0.6 \%$ \\
\hline All of above w/ lek 75 tax increase & $18.9 \%$ & $13.3 \%$ & $-28.0 \%$ & $13.0 \%$ & $12.7 \%$ & $12.4 \%$ & $-32.1 \%$ \\
\hline All above w/ lek 125 tax increase & $18.9 \%$ & $12.7 \%$ & $-31.3 \%$ & $12.3 \%$ & $12.0 \%$ & $11.6 \%$ & $-36.5 \%$ \\
\hline All of above w/ lek 175 tax increase & $18.9 \%$ & $12.2 \%$ & $-33.7 \%$ & $11.9 \%$ & $11.5 \%$ & $11.0 \%$ & $-39.6 \%$ \\
\hline
\end{tabular}

${ }^{*}$ Prevalence rates as a percent of the adult (18+) population.

${ }^{* *}$ Measured relative to the status quo in the same year, i.e., (SRp,t-SRStatus quo,t)/ SRStatus quo,t, where SRp, $t$ is the smoking rate in year $t$ with policy $p$ and SRStatus quo, $t$ is the smoking rate in year $t$ with status quo.

*** Tax increase is relative to the lek 125 price and is adjusted upward with inflation over time. 
Table 2a. Deaths attributable to smoking* predicted under status quo and different policy scenarios for males, 2007-2027

\begin{tabular}{|c|c|c|c|c|c|c|}
\hline Policy in place & 2007 & 2008 & 2012 & 2017 & 2027 & $\begin{array}{l}\text { Lives saved in } \\
\qquad 2027^{\star *}\end{array}$ \\
\hline Status quo in 2007 & 2,088 & 2,109 & 2,380 & 2,690 & 3,315 & \\
\hline Status quo with new policies & 2,088 & 2,109 & 2,364 & 2,655 & 3,224 & \\
\hline Lek 25 tax increase ${ }^{\star \star \star}$ & 2,088 & 2,109 & 2,346 & 2,614 & 3,117 & 108 \\
\hline Lek 75 tax increase & 2,088 & 2,109 & 2,318 & 2,554 & 2,960 & 265 \\
\hline Lek 125 tax increase ${ }^{\star \star \star}$ & 2,088 & 2,109 & 2,299 & 2,512 & 2,851 & 374 \\
\hline Lek 175 tax increase ${ }^{\star \star \star}$ & 2,088 & 2,109 & 2,285 & 2,482 & 2,770 & 454 \\
\hline Clean air laws & 2,088 & 2,109 & 2,344 & 2,610 & 3,109 & 115 \\
\hline Media campaign & 2,088 & 2,109 & 2,350 & 2,624 & 3,144 & 80 \\
\hline Marketing ban & 2,088 & 2,109 & 2,354 & 2,632 & 3,166 & 58 \\
\hline Strong health warnings & 2,088 & 2,109 & 2,359 & 2,643 & 3,191 & 33 \\
\hline Cessation treatment program & 2,088 & 2,109 & 2,345 & 2,606 & 3,079 & 146 \\
\hline Youth access & 2,088 & 2,109 & 2,364 & 2,655 & 3,224 & 1 \\
\hline All of above w/ lek 75 tax increase & 2,088 & 2,109 & 2,223 & 2,337 & 2,379 & 845 \\
\hline All above w/ lek 125 tax increase & 2,088 & 2,109 & 2,208 & 2,303 & 2,293 & 931 \\
\hline All of above w/ lek 175 tax increase & 2,088 & 2,109 & 2,196 & 2,279 & 2,230 & 995 \\
\hline
\end{tabular}

* Death attributable to smoking are estimated using a 1.55 relative risk for smoking.

${ }^{* *}$ Measured as the difference from the status quo in the same year.

*** Tax increase is relative to the 125 price and adjusted upward with inflation over time.

Table 2b. Deaths attributable to smoking* predicted under status quo and different policy scenarios for females, 2007-2027

\begin{tabular}{|c|c|c|c|c|c|c|}
\hline Policy in place & 2007 & 2008 & 2012 & 2017 & 2027 & $\begin{array}{l}\text { Lives saved in } \\
2027^{* *}\end{array}$ \\
\hline Status quo in 2007 & 717 & 722 & 760 & 775 & 803 & \\
\hline Status quo with new policies & 717 & 722 & 756 & 765 & 782 & \\
\hline Lek 25 tax increase ${ }^{\star \star \star}$ & 717 & 722 & 751 & 754 & 756 & 25 \\
\hline Lek 75 tax increase ${ }^{\star \star \star}$ & 717 & 722 & 744 & 738 & 719 & 62 \\
\hline Lek 125 tax increase ${ }^{\star \star *}$ & 717 & 722 & 739 & 727 & 694 & 88 \\
\hline Lek 175 tax increase ${ }^{\star \star *}$ & 717 & 722 & 735 & 718 & 675 & 107 \\
\hline Clean air laws & 717 & 722 & 751 & 753 & 754 & 27 \\
\hline Media campaign & 717 & 722 & 752 & 757 & 763 & 19 \\
\hline Marketing ban & 717 & 722 & 753 & 759 & 768 & 14 \\
\hline Strong health warnings & 717 & 722 & 755 & 762 & 774 & 7 \\
\hline Cessation treatment program & 717 & 722 & 751 & 754 & 753 & 29 \\
\hline Youth access & 717 & 722 & 756 & 765 & 782 & 0 \\
\hline All of above w/ lek 75 tax increase & 717 & 722 & 719 & 681 & 587 & 194 \\
\hline All above w/ lek 125 tax increase & 717 & 722 & 715 & 672 & 567 & 215 \\
\hline All of above w/ lek 175 tax increase & 717 & 722 & 713 & 665 & 552 & 230 \\
\hline
\end{tabular}

* Death attributable to smoking are estimated using a 1.55 relative risk for smoking

** Measured as the difference from the status quo in the same year.

*** Tax increase is relative to the 125 price and adjusted upward with inflation over time. 
predicted to fall by $2.2 \%$ in absolute terms and $3.5 \%$ in relative terms over ten years to 2017 , by $2.9 \%$ in absolute terms and $4.6 \%$ in relative terms over twenty years to 2027. Much of this decline reflects older cohorts of smokers with higher smoking rates dying and being replaced with younger, more recent cohorts with slightly lower smoking rates. For females, smoking prevalence increased in absolute terms by $0.1 \%$ between 2007 and 2008 from $18.9 \%$ to $19.0 \%$ and stayed approximately constant over the next 20 years.

A status quo taking into account the policies implemented in 2007 was also considered (and affecting smoking rates from 2008 onward). In this case, male smoking rates fall to $62.2 \%$ in 2008 , a decline of $2.9 \%$ relative to the old status quo, and to $59.1 \%$ in 2027, a decline of $3.9 \%$ relative to the old status quo. Female smoking rates fall to 18.4 in 2008 a decline of $3.0 \%$ relative to the old status quo and to $18.2 \%$ in 2027 , a decline of $0.9 \%$ relative to the old status quo.

With the policies implemented in 2007 (the new status quo), the estimated number of smoking attributable deaths in 2007 is 2,088 for males and 717 for females. Relative to 2007, male deaths are projected to increase by 567 per year by 2017 and by 1,136 per year by 2027. These increases represent the aging of cohorts with high smoking prevalence. Female deaths are projected to increase by 48 per year in 2017, and by 65 per year in 2027 . Since smoking-related deaths generally occur after the age of 40 , the effect on death rates occur with a lag. The slower increase in female deaths results from the substantially lower smoking rates for younger females, whereas for males smoking rates increase with age up until age 50 and then decline with age.

The above estimates were developed assuming an average relative risks of 1.55. Smoking-attributable deaths are also considered assuming a relative risk of 2.4 , since relative risks may be expected to rise over time. Using a relative risk of 2.4, the estimated number of smoking attributable deaths in 2007 is 3,994 $(1,761)$ for males (females), which is $1,906(1,043)$ more deaths for males (females) than with a relative risk of 1.55. For males, the difference from using the 2.4 compared to the 1.55 relative risk increases over time with 2,230 more deaths in 2017 and 2,779 more deaths by 2027. For females, the difference declines over time, with 933 more deaths by 2017 and 920 deaths by 2027 using the 2.4 compared to a 1.55 relative risk.

\section{The Effect of FCTC-consistent Policies Implemented in 2008}

An increase in taxes of lek 25, lek 75, lek 125 and lek 175 were examined. Relative to the new status quo scenario, smoking rates are projected to decline by $4.0 \%$ for males and $4.1 \%$ for females in 2008 with an increase in the cigarette excise tax of lek 25. By the end of a 20-year projection period (the year 2027), the smoking prevalence is projected to decline by about $5.3 \%$ for males and $5.6 \%$ for females. Youth smoking declines at a faster rate as a result of tax increases than adult smoking in the model, which is the primary reason that taxes continue to reduce adult smoking rates over time. Smoking rates fall more with larger increases in the tax rate. With a lek 75 increase, relative to the status quo scenario, male (female) smoking rates are projected to decline by $9.8 \%(10.0 \%)$ in 2008 , and by $13.0 \%(13.7 \%)$ by 2027 . With a lek 125 increase, male (female) smoking rates decline by $13.8 \%$
(14.1\%) in 2008 and by $18.2 \%$ (19.1\%) in 2027. With a lek 175 increase, male (female) smoking rates decline by $16.7 \%$ (17.2\%) in the first year and by $22.0 \%$ (23.0\%) after twenty years.

The projected number of deaths reflects the effectiveness of tax policy in reducing smoking. The effects of taxes on death are delayed because the greatest tax effects are on youth prevalence which does not lead to saved lives for at least twenty years because the health effects of cessation increase with time. Increasing taxes by lek 75 relative to the status quo scenario rate of lek 42 slows the growth of deaths, with 327 lives saved per year, 265 male and 62 female, by the year 2027. Increasing the tax by lek 125 further slows the growth of deaths, with 462 lives saved per year (374 male and 88 female) by the year 2027. Increasing taxes by lek 175 leads to 561 lives saved per year, 454 male and 107 female, by the year 2027 .

A total worksite ban alone is predicted to lead to a 3.9\% (3.9\%) relative reduction in the male (female) smoking prevalence relative to the status quo scenario in 2008 with a slight further reduction after that time. Comprehensive clean air laws, with both strong worksite and restaurant bans and strong enforcement and publicity, are predicted to lead to 142 (115 male and 27 female) fewer deaths per year by 2027 compared to the number of deaths under the status quo.

A heavily publicized media campaign directed at all smokers is examined (i.e., not targeted to a specific population, such as youth) relative to the current policy of no publicized campaign. For a heavily publicized campaign sustained over time, the model predicts a $2.7 \%$ immediate reduction in smoking prevalence after one year for males and females, increasing to about a $2.9 \%$ reduction over time for males and $2.8 \%$ for females. After 20 years, there is a projected 99 fewer smoking-attributable deaths per year (80 male and 19 female) compared to the status quo policy scenario.

The change from a ban on advertising to a complete ban on marketing is projected to yield a $2.0 \%$ immediate reduction in male smoking rates and about a 2.1\% relative reduction by 2027 . A complete ban on marketing is projected to avoid 120 (58 male and 62 female) smoking-attributable deaths in the year 2026.

Introducing strong health warnings is projected to yield a projected $1.0 \%$ immediate reduction in male smoking rates and about a $1.3 \%$ relative reduction in smoking prevalence by 2027 . Health warnings with strong publicity are projected to avoid 40 (33 male and 7 female) smoking-attributable deaths in the year 2027.

Youth access policies target youth smoking prevalence. Strict control of youth access yield imperceptible declines in adults rates after one year, because those under age 18 are a particularly small segment of the smoking population in Albania. The effects are projected to grow to about $0.9 \%$ for males and $0.6 \%$ for females by the year 2027. Because reductions in youth smoking rates do not affect deaths from smoking until age 36, the annual number of smokingattributable deaths does not decline much as a result of youth access policies. Only one death may be avoided per year in 2027.

A policy of mandated brief interventions delivered by health care providers along with full financial coverage of cessation treatments and well publicized quitlines with free NRT have smaller effects in the earlier years of the projection, but their impact grows over time through increased cessation rates (52). The combined cessation policies are projected to reduce adult smoking prevalence by $3.5 \%$ by 2008 relative to the status quo 
scenario, while a $4.5 \%$ reduction is obtained relative to status quo by 2027. Compared to taxes and media policies, cessation treatment policies have a smaller impact in the first year but their effects cumulate more rapidly over time. The combined cessation policies are projected to avoid 146 male and 29 female smokingattributable deaths by the year 2027 .

Research has shown that the most effective tobacco control campaigns use a comprehensive set of policy measures (56), targeting different populations and filling different needs to reduce smoking prevalence and subsequent deaths. In the model, combined policies increase the effect of advertising bans and clean air laws by about $2 \%$ through increased publicity and enforcement, and health warnings and media campaigns by $1 \%$ and $2 \%$, respectively, due to the increased publicity. The final scenario projects the effect for a combination of policies with the tobacco tax raised to lek 175 , a smoke-free environment at all worksites, a high intensity media campaign, a total advertising ban, strong health warnings, strict youth access controls, and a comprehensive smoking cessation treatment program.

In the immediate years, the smoking prevalence is projected to drop by $33.3 \%$ for males and $33.7 \%$ for females under a comprehensive policy plan relative to the status quo scenario. The smoking prevalence in 2027 is projected to drop by $41.0 \%$ for males and 39.6\% for females relative to status quo. By 2027, relative to status quo policies, we expect to see 1,225 (995 male and 230 female) fewer smoking attributable deaths annually. The projected cumulative effect of the comprehensive set provides strong encouragement for implementing a combination of policies as early as possible. The summation of smoking-attributable deaths avoided per year for all years (2008-2027) is 11,858 (9,470 male and 2,388 female) premature deaths. These calculations use a relative risk of 1.55 . With a comprehensive set of policies consistent with the FCTC and using a relative risk of 2.4, the cumulative number of premature deaths avoided increases to $24,582(18,869$ males and 5,713 females) by 2027.

\section{DISCUSSION}

This study examines results from the Albania SimSmoke model, which applies data from Albania and modified parameter values to the SimSmoke tobacco control policy simulation model. The models predictions consider long-term trends in smoking rates due to pre-policy initiation and cessation rates and short-term changes due to the addition of stricter policies.

Albania has recently increased taxes and strengthened its clean air laws and advertising restrictions. However, there is room to strengthen tobacco control policies relative to the current level of policy implementation and some benefits can be achieved even in the near future. The largest potential effect of future policies would result from a sizable increase in taxes and a comprehensive cessation treatment program. By 2027, increasing the cigarette tax to lek 175 could reduce smoking prevalence by $22 \%$, and a comprehensive cessation policy program could reduce the smoking rate by an additional $4.5 \%$. If they are enforced and publicized, media policies and stricter clean air laws also have the potential to have a sizable impact, reducing smoking rates by $3 \%$ and $4 \%$ respectively. Stricter health warnings and youth access enforcement play a lesser, but important role. Based on projections, a set of policies consistent with the FCTC could lead to a drop in smoking prevalence by more than $40 \%$.

Without effective tobacco control policies, a substantial increase in the number of deaths due to smoking is predicted. Because of the natural progression of tobacco-related illnesses, early reductions in smoking prevalence have a relatively small impact on the number of smoking-attributable deaths in the shortterm. The relative impact of a comprehensive tobacco policy in five years is small compared to the potential impact after twenty years. By 2027, with a strong set of policies, over 1,225 premature deaths could be avoided in that year alone.

Projections from the Albanian SimSmoke model should be interpreted in a conservative manner. The model is complex, and its results depend on assumptions and parameters underlying the population module, the smoking module, and each policy module.

The model distinguishes smoking and death rates by gender, but assumes that the roles of socio-demographic groups within each gender grouping remains constant. As the population shifts from rural to urban areas and becomes more affluent, smoking and death rates may be expected to change. These trends will be important to monitor in future years in Albania.

The smoking prevalence results from the smoking module depend on estimates of smoking rates, cessation, and initiation. The data on smoking rates is based on data from Albania. Reliable data was not available for relapse rates, and therefore, these rates are based on US rates. Albania had low first year cessation rates and a small percentage of ex-smokers relative to the United States. Future research should focus both on the reasons for lower cessation rates and on developing measures of relapse rates for Albania in order to better understand and develop policies to improve cessation. Greater access to cessation treatments is one factor that may increase cessation rates. The results from the smoking module also depend on the assumption that initiation, cessation, and relapse are constant over time except due to policy-induced changes in future years. A tax increase occurred in the year prior to the baseline year and its effects may have temporarily increased baseline cessation rates or reduced initiation rates. In addition, as incomes rise and Albania becomes more Westernized, female smoking initiation rates may increase.

The estimated relative risk for total deaths of smokers is based on data from Taiwan and Korea. Compared to these nations, however, quantity smoked per smoker is high and has been rising in Albania and death rates from other diseases may fall in Albania over time. Consequently, the model may understate smokingattributable deaths. With a relative risk of 2.4, the same as for the US $(1,34,35)$, the number of projected deaths substantially increases. Notably, the estimates of the impact of various tobacco control measures also do not take into account the deaths attributable to exposure to second hand smoke. In Albania, considering the high number of male smokers and low number of female smokers, exposure to smoke among non-smokers is likely to have a large adverse impact on health. Furthermore, the model does not consider monetary savings that may accrue through reduced medical costs and productivity losses. These savings will bring an additional positive impact of tobacco control policies.

The policy modules depend on parameters for the effect on initiation and cessation, and assumptions about the interdependence of policies. Knowledge about the effects of each policy varies (6). 
For example, studies have obtained relatively consistent results for the effects of price. There are also studies of clean air laws, with results somewhat less consistent than those of price, that fall into realistic ranges. Studies on the effects of media, however, provide a broad range of estimates, and those on advertising bans are even less consistent. In addition, the policy parameters for the model are based primarily on studies of the US, Australia, and European nations as a whole. Studies should be done for Albania and other non-Westernized countries, not only to gauge the initial effect of policies, but also to discover how the effects of those policies will unfold over time. There should be special attention paid to the effect of tobacco control policies on smuggling. Better information is also needed about the interactions between policies and how that affects smoking rates. Even without fully understanding the effects and interactions between different policies, it is possible to recognize the value and necessity of a multifaceted approach.

This study is the first to evaluate the effects of comprehensive tobacco control policy in Albania and seeks to understand both the individual and combined impact of selected policies. The model relies on simplifying assumptions because of limitations on available information. Highlighting the data gaps should guide future smoking surveillance efforts, enabling model users or researchers to approach policy evaluation from a more comprehensive baseline. Further development and implementation of tobacco control policies will also hinge on evaluations showing the effective of interventions. As new evidence becomes available, that information may be easily incorporated into the model.

In sum, the model indicates substantial benefits from improving tobacco control policies in a way that is consistent with the FCTC. When the cigarette tax is appreciably increased, strong clean air and youth access laws are implemented and enforced, a strict advertising law is promulgated and enforced, strong warning labels are required, a high publicity media campaign is coordinated with the other policies, and a comprehensive cessation treatment program is implemented, the smoking rate is projected to fall by over $40 \%$ in relative terms and over 1,225 premature deaths are to be avoided per year by 2027. A large increase in taxes alone would substantially reduce the number of lives lost to smoking. Tax increases are also likely to increase government tax revenues (57), part of which could be earmarked to enforce and publicize other policies.

The availability of these projections and analyses allows for a well informed allocation of the limited government resources available for implementing policies. It behooves policymakers and tobacco control advocates to concentrate on the most effective approaches to curbing initiation and encouraging smoking cessation such as cigarette taxes, clean air laws, cessation treatment policies, advertising restrictions, and media campaigns.

\section{REFERENCES}

1. U.S. Department of Health and Human Services. Reducing the health consequences of smoking: 25 years of progress. A report of the Surgeon General. DHHS publication no. (CDC) 89-8411. Rockville: U.S. Department of Health and Human Services, Public Health Service, Centers for Disease Control and Prevention, Center for Chronic Disease Prevention and Health Promotion, Office on Smoking and Health; 1989.

2. U.S. Department of Health and Human Services. The health benefits of smoking cessation: a report of the Surgeon General. DHHS publication no. (CDC) 90-8416. Rockville: U.S. Department of Health and Human Services, Public Health Service, Centers for Disease Control and Prevention, Center for Chronic Disease Prevention and Health Promotion, Office on Smoking and Health; 1990.

3. Peto R, Lopez AD. Future worldwide health effects of current smoking patterns. In: Koop CE, Pearson CE, Schwarz M, editors. Critical issues in global health. San Francisco: Jossey-Bass; 2000. p. 154-161.

4. Bobak M, Marmot M. East-West mortality divide and its potential explanations: proposed research agenda. BMJ. 1996 Feb 17;312(7028):421-5.

5. Hopkins DP, Briss PA, Ricard CJ, Husten CG, Carande-Kulis VG, Fielding JE, et al; Task Force on Community Preventive Services. Reviews of evidence regarding interventions to reduce tobacco use and exposure to environmental tobacco smoke. Am J Prev Med. 2001 Feb;20(2 Suppl):16-66.

6. Levy DT, Chaloupka F, Gitchell J. The effects of tobacco control policies on smoking rates: a tobacco control scorecard. J Public Health Manag Pract. 2004 Jul-Aug;10(4):338-53.

7. U.S. Department of Health and Human Services. Preventing tobacco use among young people: a report of the Surgeon General. Atlanta: Centers for Disease Control and Prevention, National Center for Chronic Disease Prevention and Health Promotion, Office on Smoking and Health; 1994.

8. U.S. Department of Health and Human Services. Healthy people 2010. Atlanta: Centers for Disease Control and Prevention, Office of Disease Prevention and Health Promotion; 2000.

9. Taylor DH Jr., Hasselblad V, Henley SJ, Thun MJ, Sloan FA. Benefits of smoking cessation for longevity. Am J Public Health. 2002 Jun;92(6):9906. Erratum in: Am J Public Health 2002 Sep;92(9):1389.

10. Shuperka R. Living standard measurement survey. Tiranna: The World Bank; 2002.

11. Hu TW, Sung HY, Keeler TE. Reducing cigarette consumption in California: tobacco taxes vs an anti-smoking media campaign. Am J Public Health. 1995 Sep;85(9):1218-22.

12. Hu TW, Sung HY, Keeler TE The state antismoking campaign and the industry response: the effects of advertising on cigarette consumption in California. Am Econ Rev. 1995 May;85(2):85-90.

13. Farrelly MC, Pechacek TF, Chaloupka FJ. The impact of tobacco control program expenditures on aggregate cigarette sales: 1981-2000. J Health Econ. 2003 Sep;22(2):843-59. Erratum in: J Health Econ. 2004 Mar;23(2):419.

14. Homer JB, Hirsch GB. System dynamics modeling for public health: background and opportunities. Am J Public Health. 2006 Mar;96(3):452-8.

15. Levy DT, Bauer JE, Lee HR. Simulation modeling and tobacco control: creating more robust public health policies. Am J Public Health. 2006 Mar;96(3):494-8.

16. Mendez D, Warner KE, Courant PN. Has smoking cessation ceased? Expected trends in the prevalence of smoking in the United States. Am J Epidemiol. 1998 Aug 1;148(3):249-58.

17. Mendez D, Warner KE. Adult cigarette smoking prevalence: declining as expected (not as desired). Am J Public Health. 2004 Feb;94(2):251-2.

18. Tengs TO, Osgood ND, Lin TH. Public health impact of changes in smoking behavior: results from the Tobacco Policy Model. Med Care. 2001 Oct;39(10):1131-41.

19. Tengs TO, Ahmad S, Moore R, Gage E. Federal policy mandating safer cigarettes: a hypothetical simulation of the anticipated population health gains or losses. J Policy Anal Manage. 2004 Aug,23(4):857-72.

20. Ahmad S. Increasing excise taxes on cigarettes in California: a dynamic simulation of health and economic impacts. Prev Med. 2005 Jul;41(1):276-83.

21. Ahmad S, Billimek J. Estimating the health impacts of tobacco harm reduction policies: a simulation modeling approach. Risk Anal. 2005 Aug;25(4):801-12.

22. Ahmad S, Billimek J. Limiting youth access to tobacco: comparing the long-term health impacts of increasing cigarette excise taxes and raising the legal smoking age to 21 in the United States. Health Policy. 2007 Mar;80(3):378-91.

23. Levy DT, Cummings KM, Hyland A. A simulation of the effects of youth initiation policies on overall cigarette use. Am J Public Health. 2000 Aug;90(8):1311-4.

24. Levy DT, Nikolayev L, Mumford E. Recent trends in smoking and the role of public policies: results from the SimSmoke tobacco control policy simulation model. Addiction. 2005 Oct;100(10):1526-36.

25. Levy DT, Nikolayev L, Mumford E, Compton C. The Healthy People 2010 smoking prevalence and tobacco control objectives: results from the SimSmoke tobacco control policy simulation model (United States). Cancer Causes Control. 2005 May;16(4):359-71. 
26. Levy DT, Chaloupka F, Gitchell J, Mendez D, Warner KE. The use of simulation models for the surveillance, justification and understanding of tobacco control policies. Health Care Manag Sci. 2002 Apr;5(2):113-20.

27. McWhorter WP, Boyd GM, Mattson ME. Predictors of quitting smoking: the NHANES I followup experience. J Clin Epidemiol. 1990;43(12):1399-405.

28. Gilpin EA, Pierce JP, Farkas AJ. Duration of smoking abstinence and success in quitting. J Natl Cancer Inst. 1997 Apr 16;89(8):572-6.

29. Shultz JM, Novotny TE, Rice DP. Quantifying the disease impact of cigarette smoking with SAMMEC II software. Public Health Rep. 1991 May-Jun;106(3):326-33.

30. Centers for Disease Control and Prevention. Cigarette smoking among adults - United States, 1998. MMWR Morb Mortal Wkly Rep. 2000 Oct 6;49(39):881-4

31. Wen CP, Tsai SP, Chen CJ, Cheng TY. The mortality risks of smokers in Taiwan; Part I: cause-specific mortality. Prev Med. 2004 Sep;39(3):528-35.

32. Jee SH, Lee JK, Kim IS. Smoking-attributable mortality among Korean adults: 1981-2003. Korean J Epidemiol. 2006 Jun;28(1):92-9.

33. Peto R. Influence of dose and duration of smoking on lung cancer rates. IARC Sci Publ. 1986;(74):23-33.

34. Thun MJ, Myers DG, Day-Lally C, Namboodiri NM, Calle EE, Flanders $\mathrm{WD}$, et al. Age and the exposure-response relationships between cigarette smoking and premature death in Cancer Prevention Study II. In: Shopland DR, Burns DM, Garfinkel L, et al, editors. Changes in cigarette related disease risks and their implication for prevention and control Rockville: National Cancer Institute; 1997. p. 383-475.

35. Burns D, Garfinkel L, Samet J, edsitors. Changes in cigarette-related disease risks and their implication for prevention and control. Bethesda: National Institutes of Health; 1997.

36. Friend K, Levy DT. Reductions in smoking prevalence and cigarette consumption associated with mass-media campaigns. Health Educ Res. 2002 Feb;17(1):85-98.

37. Friend K, Levy DT. Smoking treatment interventions and policies to promote their use: a critical review. Nicotine Tob Res. 2001Nov;3(4):299-310.

38. Levy DT, Friend K. Gauging the effects of mass media policies: what do we need to know? J Public Health Manag Pract. 2000 May;6(3):95106.

39. Levy DT, Friend K. A framework for evaluating and improving clean indoor air laws. J Public Health Manag Pract. 2001 Sep;7(5):87-96.

40. Levy DT, Friend K. A simulation model of tobacco youth access policies. J Health Polit Policy Law. 2000 Dec;25(6):1023-50.

41. Levy DT, Friend K. The effects of clean indoor air laws: what do we know and what do we need to know? Health Educ Res. 2003 Oct;18(5):592609.

42. Hughes JR. Reduced smoking: an introduction and review of the evidence. Addiction. 2000 Jan;95 Suppl 1:S3-7.
43. Hymowitz N, Cummings KM, Hyland A, Lynn WR, Pechacek TF, Hartwell TD. Predictors of smoking cessation in a cohort of adult smokers followed for five years. Tob Control. 1997;6 Suppl 2:S57-62.

44. Hymowitz N, Sexton M, Ockene J, Grandits G; MRFIT Research Group. Baseline factors associated with smoking cessation and relapse. Prev Med. 1991 Sep;20(5):590-601.

45. Levy DT, Cummings KM, Hyland A. Increasing taxes as a strategy to reduce cigarette use and deaths: results of a simulation model. Prev Med. 2000 Sep;31(3):279-86.

46. Chaloupka FJ, Hu TW, Warner KE, Jacobs R, Yurekli A. The taxation of tobacco products. In: Chaloupka FJ, Jha P, editors. Tobacco control in developing countries. New York: Oxford University Press; 2000. p. 237-72.

47. Guindon EG, Perucic A-M, Boisclair D. Higher tobacco prices and taxes in South-East Asia: an effective tool to reduce tobacco use, save lives and generate revenue. Washington,D.C.: The World Bank; 2003.

48. Sung HY, Hu TW, Keeler TE Cigarette taxation and demand: an empirical model. Contemp Econ Policy. 1994;12(3):91-100.

49. Levy DT, Friend K, Polishchuk E. Effect of clean indoor air laws on smokers: the clean air module of the SimSmoke computer simulation model. Tob Control. 2001 Dec;10(4):345-51.

50. Levy DT, Friend K. A computer simulation model of mass media interventions directed at tobacco use. Prev Med. 2001Mar;32(3):284-94.

51. Levy DT, Friend K. A simulation model of policies directed at treating tobacco use and dependence. Med Decis Making. 2002 Jan-Feb;22(1):6-17.

52. Levy DT, Friend K. Examining the effects of tobacco treatment policies on smoking rates and smoking related deaths using the SimSmoke computer simulation model. Tob Control. 2002 Mar;11(1):47-54.

53. Fiore M, Bailey W, Cohen S, Dorfman S, Goldstein M, Gritz E, et al. Treating tobacco use and dependence. Clinical practice guideline. Rockville: U.S. Department of Health and Human Services, Public Health Service; 2000.

54. Zhu SH, Anderson CM, Johnson CE, Tedeschi G, Roeseler A. A centralized telephone service for tobacco cessation: the California experience. Tob Control. 2000;9 Suppl 2:II48-55.

55. Cummings KM, Fix B, Celestino P, Carlin-Menter S, O’Connor R, Hyland A. Reach, efficacy, and cost-effectiveness of free nicotine medication giveaway programs. J Public Health Manag Pract. 2006 Jan-Feb;12(1):37-43.

56. Jha P, Chaloupka F, editors. Tobacco control in developing countries. New York: Oxford University Press; 2000.

57. Merriman D, Yurekli A, Chaloupka F. How big is the worldwide cigarette smuggling problem. In: Jha P, Chaloupka F, editors. Tobacco control in developing countries. New York: Oxford University Press; 2000. p. 365-92.

Received February 26, 2008 Accepted June 25, 2008 